Research, Society and Development, v. 9, n. 8, e704985580, 2020

(CC BY 4.0) | ISSN 2525-3409 | DOI: http://dx.doi.org/10.33448/rsd-v9i8.5580

\title{
Edward Wilson: um testamento aos jovens cientistas
}

Edward Wilson: a testament to young scientists

Edward Wilson: un testamento para los jóvenes científicos

Recebido: 12/06/2020 | Revisado: 12/06/2020 | Aceito: 12/07/2020 | Publicado: 30/07/2020

\section{Rodrigo Ferraz Ramos}

ORCID: https://orcid.org/0000-0002-6414-376X

Universidade Federal de Santa Maria, Brasil

E-mail: rodrigoferrazramos@gmail.com

\section{Resumo}

Primeiro a paixão, depois os estudos. Esse é o conselho de Edward Wilson aos jovens pesquisadores. Na obra intitulada "Cartas a um jovem cientista", Wilson compartilha com o público a sua paixão pelo mundo natural e pela descoberta. Ser um cientista, antes de tudo, é ter paixão por resolver problemas. É necessário dedicação, criatividade e muito estudo, mas, o resultado é a descoberta de um mundo natural em evolução. A obra de Wilson é um verdadeiro testamento aos pesquisadores aspirantes e futuros cientistas.

Palavras-chave: Biodiversidade; Ciência; Criatividade; Epistemologia; Filosofia.

\begin{abstract}
First your passion, then your studies. This is Edward Wilson's advice to young scientists. In the work entitled "Letters to a young scientist", Wilson shares with the public his passion for the natural world and for discovery. Being a scientist, before of all, is having a passion for solving problems. It takes dedication, creativity and a lot of study, but the result is the discovery of an evolving natural world. Wilson's work is a true testament to young researchers and future scientists.
\end{abstract}

Keywords: Biodiversity; Science; Creativity; Epistemology; Philosophy.

\section{Resumen}

Primero su pasión, después sus estudios. Este es el consejo de Edward Wilson para jóvenes investigadores. En el libro titulado "Cartas a un joven científico", Wilson comparte con el público su pasión por el mundo natural y por el descubrimiento científico. Ser científico, en primer lugar, es tener una pasión por resolver problemas. Se necesita dedicación, creatividad 
y mucho estudio, pero el resultado es el descubrimiento de un mundo natural en evolución. El libro de Wilson es un verdadero testamento para jóvenes investigadores y futuros científicos.

Palabras clave: Biodiversidad; Ciencias; Creatividad; Epistemología; Filosofía.

\section{Resenha da obra de "Cartas a um jovem cientista" de Edward Osborne Wilson"}

Qual a sua reação se alguém aconselhasse você a colocar a sua paixão na frente dos estudos? Pouco confiável? E se essa recomendação viesse de um dos maiores estudiosos da atualidade? Pois bem, para o célebre biólogo Edward Wilson, esse é o caminho a seguir: primeiro a paixão, depois os estudos. Ao longo da presente resenha, será apresentado essa instigante visão que Wilson propõe aos jovens pesquisadores.

Edward Osborne Wilson, professor da Universidade de Harvard, é considerado um dos biólogos mais renomados do mundo. Reconhecido por ser um naturalista, pesquisador, escritor e apaixonado por formigas. Wilson é o pai da Sociobiologia e um dos responsáveis por popularizar o termo biodiversidade. Ao longo da sua proeminente carreira, acumulou diversas experiências, ao qual compartilha na forma de conselhos à pesquisadores aspirantes na obra intitulada "Cartas a um jovem cientista".

Para Wilson, um princípio importante que acompanha a vida de muitos cientistas, é a paixão pelo objeto de estudo:

Ponha a paixão na frente dos estudos. Descubra de algum modo aquilo que você mais quer fazer na ciência, na tecnologia ou em alguma outra profissão relacionada a ciência. Obedeça a essa paixão enquanto ela durar. Alimente-a com conhecimento que a mente precisa para se desenvolver. [...] A decisão e o trabalho duro baseados em uma paixão duradoura nunca vão desaparecer (Wilson 2015, p. 21).

Para o autor, o caminho a seguir é buscando explorar áreas do conhecimento pouco investigadas. Se um tema for emergente, e ainda não tiver experts reconhecidos na área, essa é uma ótima oportunidade. Busque identificar um problema original e avalie a sua potencialidade. Se a resolução do problema apresenta uma grande dificuldade, pois bem, melhor ainda. Como adverte Wilson: "na busca por descobertas científicas, cada problema é uma oportunidade. Quanto mais difícil o problema, maior a importância de sua solução" (Ibid, 2015 p. 38).

Mas como desenvolver e exercitar o processo criativo? Ora, para Wilson a resposta está no hábito de fantasiar cenários sobre a ciência. Se uma ideia surgir, permita-se sonhar 
acordado. É importante permitir-se criar cenários hipotéticos e imaginar caminhos a seguir. Esse é um exercício que estimula a criatividade, a capacidade de resolução de problemas e é um gatilho que permite emergir novidades. Em síntese, como defende Wilson, "o cientista ideal pensa como um poeta e só então trabalha como um contador. Tenha em mente que os inovadores, tanto na literatura quanto na ciência, são basicamente sonhadores e contadores de histórias" (Ibid, 2015, p. 59).

Wilson destaca a importância de um mentor para o início de uma carreira científica. Um orientador inspirador pode influenciar positivamente as escolhas e caminhos de seus orientandos. De fato, Wilson se tornou um dos maiores pesquisadores de formigas no mundo seguindo os passos de seu orientador William Brown, na época um dos raros especialistas em formigas no mundo. Ainda, o autor aconselha a todos os jovens pesquisadores:

Vá aonde há menos coisas acontecendo. [...] ao seguir o caminho menos convencional, e ao ter um mentor inspirador como Bill Brown, eu tive muito mais facilidades. Descobri cedo a oportunidade especial de conduzir uma pesquisa científica em tocos apodrecendo e em outros microrganismos que são a fundação do mundo vivo, mas que na época e ainda hoje são tão facilmente subestimados (Ibid, 2015, p. 104).

Mas o que fazer quando você encontrar o seu nicho de estudo? O próximo passo é a dedicação ao estudo. Certamente é necessário conhecer o seu assunto profundamente. Em termos gerais, a dedicação ao estudo tem que ser suficiente para tornar-se um expert na área. O compromisso com o conhecimento e a verdade tem que ser um compromisso moral. Antes de qualquer descoberta haverá muitas horas de leitura, imaginação e trabalho. A descoberta da novidade é posterior ao domínio do que já se sabe sobre o assunto. Como salienta Wilson:

Para fazer descobertas na ciência, tanto as pequenas quanto as importantes, você deve ser um expert nos tópicos abordados. Ser um expert inovador exige comprometimento. Comprometimento com um assunto implica trabalho duro e contínuo (Ibid, 2015, p. 104).

Contudo, é necessário ir adiante. Não basta ser somente um expert em uma determinada área do conhecimento. É necessário ser um observador atento. Há diversos fenômenos que podem ocorrer ao longo de um experimento que não eram esperados ou não foram percebidos anteriormente. Em vez de ignorar a situação considerando o fenômeno inesperado como o resultado causal de um erro experimental, seria aconselhável, na percepção de Wilson, pensar no fenômeno como uma resposta possível a perguntas que ainda 
não foram feitas. A observação de um fenômeno inesperado podem ser a resposta para uma lacuna no conhecimento.

Portanto, procure principalmente coisas estranhas, pequenos desvios e fenômenos que parecem triviais de início, mas que examinados mais de perto podem se mostrar importantes. Construa cenários em sua cabeça ao fazer a varredura de informações que estão disponíveis para você. Torne a perplexidade algo útil (Ibid, 2015, p. 147).

Para Wilson, a descoberta científica também está intimamente relacionada com o olhar atento do pesquisador, a sua visão criativa do mundo natural e de sua capacidade de fazer perguntas corretas. As perguntas podem ser específicas, direcionadas a fenômenos que atuam em pequena escala. Mas a ciência também se preocupa com grandes questões. Quais os processos inerentes que criam a diversidade biológica na Terra? Quais os fatores que explicam os padrões de distribuições das espécies? Quais os mecanismos que operam para que uma espécie tenha sucesso no domínio de um nicho ecológico? Qual o papel da biodiversidade na manutenção dos serviços ecossistêmicos no nosso planeta?

Justamente essas questões supracitadas ocuparam a mente de Wilson desde o início de sua carreira científica, tanto que foram temas de discussões em outras grandes obras de sua autoria, como "A criação: como salvar a vida na terra" (2008) e "Diversidade da Vida" (2012). Na visão de Wilson, os jovens cientistas também devem estar atentos a essas questões, pois em suas pesquisas básicas, estudando fenômenos de menor abrangência, podem contribuir para montar quebra-cabeças que permite reforçar ou não as teorias gerais que dão suporte a esses fenômenos.

Por fim, Wilson em seu "testamento" delimita um panorama acerca dos dilemas éticas que todo pesquisador poderá enfrentar. Todo pesquisador poderá enfrentar dilemas filosóficos, como a criação de organismos artificiais, uso de animais em experimentos cirúrgicos ou com drogas sintéticas, uso da inteligência artificial, entre outros. Certamente esses dilemas fazem parte da vida de muitos cientistas. Mas a principal preocupação de Wilson é em relação ao convívio com outros cientistas. A ciência avança através da colaboração entre os pesquisadores, sociedade e instituições. Mas a ciência também é uma arena de competividade entre os pesquisadores, onde alguns tem mais recursos e podem alcançar mais rapidamente os objetivos de carreira.

Contudo, Wilson destaca a importância de seguir na busca de ideias originais e dar os devidos créditos e reconhecimento aos colegas de profissão. Eles certamente farão o mesmo. 
A busca da verdade é um compromisso moral dos cientistas e as descobertas são um legado para a ciência e à humanidade.

Ainda, é importante destacar que na obra Wilson apresentou suas ideias através de um diálogo apaixonado e direto com o leitor. Poucas obras conseguem trazer ao público experiências inéditas de toda uma vida dedicada a descoberta do mundo natural. As experiências pessoais narradas por Wilson são inspiradoras e certamente influenciarão as escolhas de diversos jovens pesquisadores. Mais do que um cientista apaixonado pela sua área de estudo, Wilson tornou-se um comunicador científico e disseminador de ideias e possibilidades.

\title{
Referências
}

Wilson, E. O. (2015) Cartas a um jovem cientista. $1^{\text {a }}$ ed. São Paulo: Companhia das Letras, 202.

Wilson, E. O. (2012) Diversidade da vida. São Paulo: Companhia das Letras, 525.

Wilson, E. O. (2008) A criação: como salvar a vida na terra. São Paulo: Companhia das Letras, 192.

\section{Porcentagem de contribuição de cada autor no manuscrito}

\author{
Rodrigo Ferraz Ramos - 100\%
}

